\title{
Nonisothermal Crystallization Behavior of In-Situ Formed Polyethylene/ Montmorillonite (PE/MMT) Nanocomposites Through Ethylene Copolym- erization
}

\author{
Baoping Shi ${ }^{\mathrm{a}}$, Cun-Yue Guo*, ${ }^{*}$, Yucai Ke ${ }^{\mathrm{b}}$, Mingge Zhang ${ }^{\mathrm{b}}$ and Youliang $\mathrm{Hu}^{\mathrm{b}}$ \\ ${ }^{a}$ School of Chemical and Biological Engineering, Taiyuan University of Science and Technology, Taiyuan 030021, P. R. \\ China \\ ${ }^{b}$ Institute of Chemistry, Chinese Academy of Sciences, Beijing 100190, P. R. China
}

\begin{abstract}
PE/MMT nanocomposites containing different amount of MMT were measured for isothermal crystallization. The combination of Ozawa equation and Avrami equation was found applicable in explaining the crystallization behavior of the nanocomposites. In certain range of MMT loadings, MMT particles played the role of nucleating agents that promoted the crystallization rate of the polymer matrix, thus making the adjustment of the crystallinity of PE nanocomposites flexible and convenient.
\end{abstract}

Keywords: Nonisothermal crystallization, polyethylene, nanocomposites.

\section{INTRODUCTION}

Polymer nanocomposites that possess dramatically improved thermal, physical, electronic and optical properties have been discovered due to the addition of only a small amount of the inorganic modifiers [1-3]. Polyolefins, including mainly polyethylene and polypropylene, are a kind of crystalline thermoplastic polymers and have found applications in almost every field relating to people's daily life. To form polymer nanocomposites with various fillers is an efficient method to further improve the physical properties of polyolefin materials. Successful chemical methods have been developed to prepare PE/MMT nanocomposites by copolymerization of ethylene with a dual functional catalyst system intercalated into MMT layers [4-6].

The crystallization behavior of polymeric materials and their composites exerts great influence on the mechanical properties and processability [7-14]. In practical application, different crystallization rates are required. Under certain circumstances, e.g., injection molding, where rapid crystallization rates are unavoidable, various nucleating agents have to be added to accelerate the crystallization rate of polyolefin.

In this regard, polyolefin-based nanocomposites display themselves as optimum examples in the combination of composites fabrication and introduction of nucleating agents. The nanoparticles of MMT dispersed in the polymeric matrix are believed to play a role of nucleating agents in the crystallization process. Up to now, research on the crystallization kinetics of polyolefin/montmorillonite (POE/MMT) nanocomposites has been mostly focused on polypropylene/montmorillonite (PP/MMT) nanocomposites [9-11, 1517] and polystyrene/montmorillonite (PS/MMT) nanocom-

*Address correspondence to this author at the Institute of Chemistry, Chinese Academy of Sciences, Beijing 100190, P. R. China; Tel: +86-1062560247; Fax: +86-10-62559373; E-mail: cyguo@iccas.ac.cn posites [18], and relatively little study on that of PE/MMT nanocomposites [19].

In this paper, differential scanning calorimetry (DSC) analysis was employed to investigate the dependence of the crystallization behavior of the as-prepared PE/MMT nanocomposites on the content of layered silicates, crystallization temperatures and cooling rates. It's expected, upon completion of such investigations, that useful information can be obtained with regard to the processability and even the preparation of high performance PE/MMT nanocomposites through ethylene polymerization method.

\section{EXPERIMENTAL}

\section{Materials}

PE/MMT nanocomposites were prepared as follows. Ethylene copolymerization was conducted in a $2 \mathrm{~L}$ stainless steel autoclave. Before each run, the autoclave was heated up to $90{ }^{\circ} \mathrm{C}$ under vacuum for $4 \mathrm{~h}$ and cooled down to room temperature. After transferring $0.7 \mathrm{~L}$ of hexane to the reactor, prescribed amount of MAO/MMT-supported iron-based diimine complex suspended in hexane was transferred and the autoclave was heated to required temperature while the autoclave was pressurized to $0.7 \mathrm{MPa}$ with ethylene. The autoclave reactor was cooled down to room temperature after $15 \mathrm{~min}$ and the ethylene pressure was slowly lowered to be atmospheric. $10 \mu \mathrm{mol}$ of $\mathrm{rac}-\mathrm{Et}(\mathrm{Ind})_{2} \mathrm{ZrCl}_{2}$ in toluene was transferred into the autoclave with $0.3 \mathrm{~L}$ of hexane, the reactor was maintained at the same temperature and ethylene pressure as those of the first step to perform the copolymerization of ethylene with $\alpha$-olefins produced in situ from the first step, a process proceeded all the time until the copolymerization was terminated after $2 \mathrm{~h}$. The polymers were precipitated in $5 \mathrm{wt} \%$ acidified ethanol, washed with ethanol, and dried to constant weight under vacuum. Four samples containing different amounts of MMT were employed which are denoted as PE/MMT1 $(\mathrm{MMT}=0.2 \mathrm{wt} \%)$, PE/MMT2 
$(\mathrm{MMT}=1.0 \mathrm{wt} \%)$, PE/MMT3 $(\mathrm{MMT}=2.4 \mathrm{wt} \%)$, and $\mathrm{PE} / \mathrm{MMT} 4(\mathrm{MMT}=4.0 \mathrm{wt} \%)$. For comparison, neat PE synthesized in similar method was used as the control sample.

\section{DSC Analysis}

Crystallization properties were studied by using a Perkin Elmer DSC-7 differential scanning calorimeter (DSC). Samples were heated from room temperature to $200{ }^{\circ} \mathrm{C}$ at a rate of $200 \mathrm{~K} / \mathrm{min}$ under a nitrogen atmosphere and held for 10 min to destroy any residual nuclei before cooling at the desired rate $(5,10,15$, and $20 \mathrm{~K} / \mathrm{min})$ to room temperature.

\section{RESULTS AND DISCUSSION}

Fig. (1) depicts the DSC curves of PE/MMT nanocomposites with different loading of MMT when a cooling rate of $10 \mathrm{~K} / \mathrm{min}$ was adopted. Also reflected in Table 1 are some important parameters for this process.

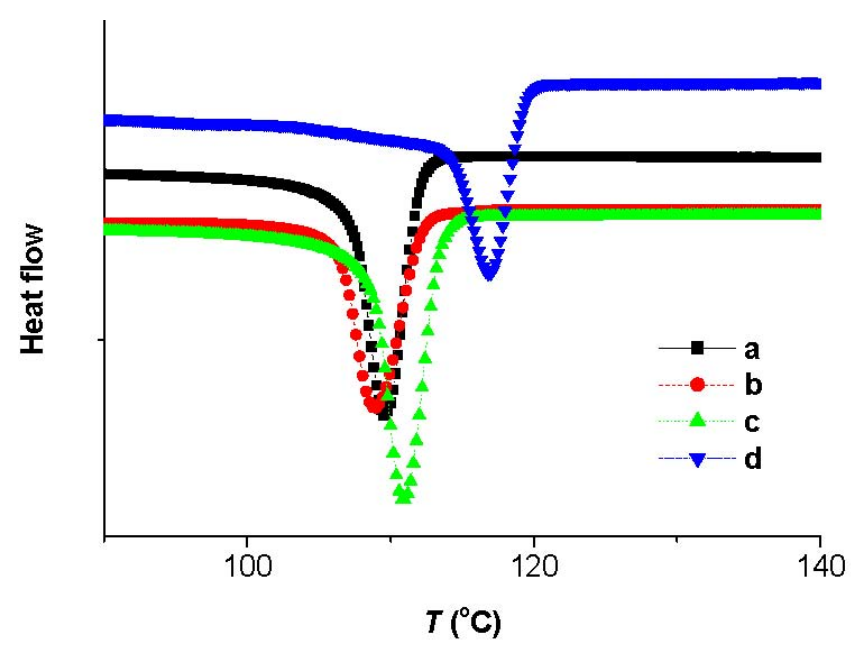

Fig. (1). DSC curves of different samples cooling at $10 \mathrm{~K} / \mathrm{min}$ : (a) PE; (b) PE/MMT1 (MMT = 0.2 wt $\%$ ); (c) PE/MMT2 $(\mathrm{MMT}=1.0$ $\mathrm{wt} \%) ;(\mathbf{d})$ PE/MMT3 (MMT $=2.4 \mathrm{wt} \%)$.

There was no significant change observed in the melting temperatures of polyethylene matrix upon the addition of MMT (Table 1). Compared to neat PE, values of $T_{\text {cmax }}$ and $T_{\mathrm{ci}}$ increased by ca. $6{ }^{\circ} \mathrm{C}$ and $5{ }^{\circ} \mathrm{C}$ respectively, whereas the $t_{1 / 2}$ value shortened as to the PE/MMT nanocomposites containing less than $2 \mathrm{wt} \%$ MMT. So a suitable amount of MMT in the nanocomposites is effective in regulating the crystallization rates.
In practice, nonisothermal conditions are more common. In the process of nonisothermal crystallization, polymeric materials actually experience melt cooling and crystallization in different temperature zones. To investigate the nonisothermal crystallization Ozawa equation (1) is always used [20].

$\log \left[-\ln \left(1-X_{T}\right)\right]=\log K_{T}-n \log R$

Where $K_{T}$ is the cooling function at $T, n$ is Ozawa index that is related to crystallization mechanism, and $R$ is the cooling rate.

Fig. (2) reflects the relationship between $\log \left[-\ln \left(1-X_{T}\right)\right]$ and $\log R$ for the nonisothermal crystallization of PE/MMT nanocomposites employing Ozawa equation. It's obvious that the data dots were not in parallel lines, implying the difficulty in the determination of $n$. Also impossible is the understanding of crystallization under nonisothermal conditions. Several factors are responsible for the inapplicability of Ozawa equation in this case. Firstly, in data treatment, Ozawa equation ignores the secondary crystallization while the crystalline domains realized might vary at different cooling rates in an actually comparatively greater $R$ range. In the temperature range for this case, some high cooling rates occurred in the primary crystalline domain whereas low cooling rates, e.g. $5 \mathrm{~K} / \mathrm{min}$, took place in the secondary crystalline domain. So there is unnecessarily a linear relationship between the crystallization degree and the cooling rates. Secondly, Ozawa parameters are related to $n$ and $k$ in Avrami equation, and $n$ and $k$ are dependant on temperatures. Because the crystalline domains were different in a broader cooling rate range, the values of $n$ and $k$ are not constant even at the same temperature. So the Ozawa parameters are not constant accordingly. Apart from the effects of crystallization temperature zone and the cooling rate, these parameters were also related with the volume function arising from the deformation caused by the crystallization. Owing to the uncertainty of these parameters, it's hard to establish a simple Ozawa equation by integration even the same temperatures are employed.

Therefore, for the same sample at different temperatures, no parallel linearity could be obtained for $\log \left[-\ln \left(1-X_{T}\right)\right]$ and $\log R$ relationship if the cooling rate range is greater. This had been confirmed in the present study. In a word, Ozawa indexes are difficult to analyze the crystallization mechanism, to say nothing of reflecting real nonisothermal crystallization processes.

For nonisothermal cystallization, the following equation (2) establishes:

Table 1. Crystallization Parameters of PE/MMT Nanocomposites Cooling at 10 K/min

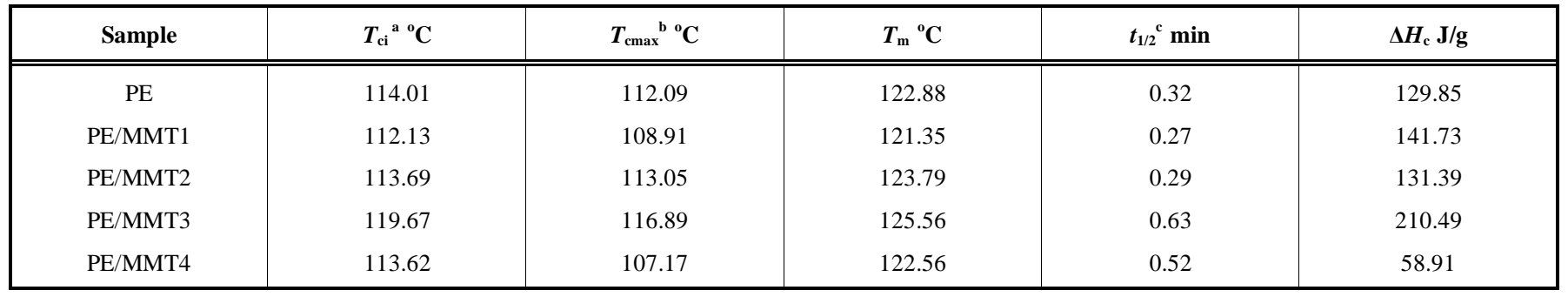

Notes: ${ }^{\mathrm{a}}$ initial crystallization temperatures; ${ }^{\mathrm{b}}$ maximum crystallization temperatures; ${ }^{\mathrm{c}}$ half crystallization time. 

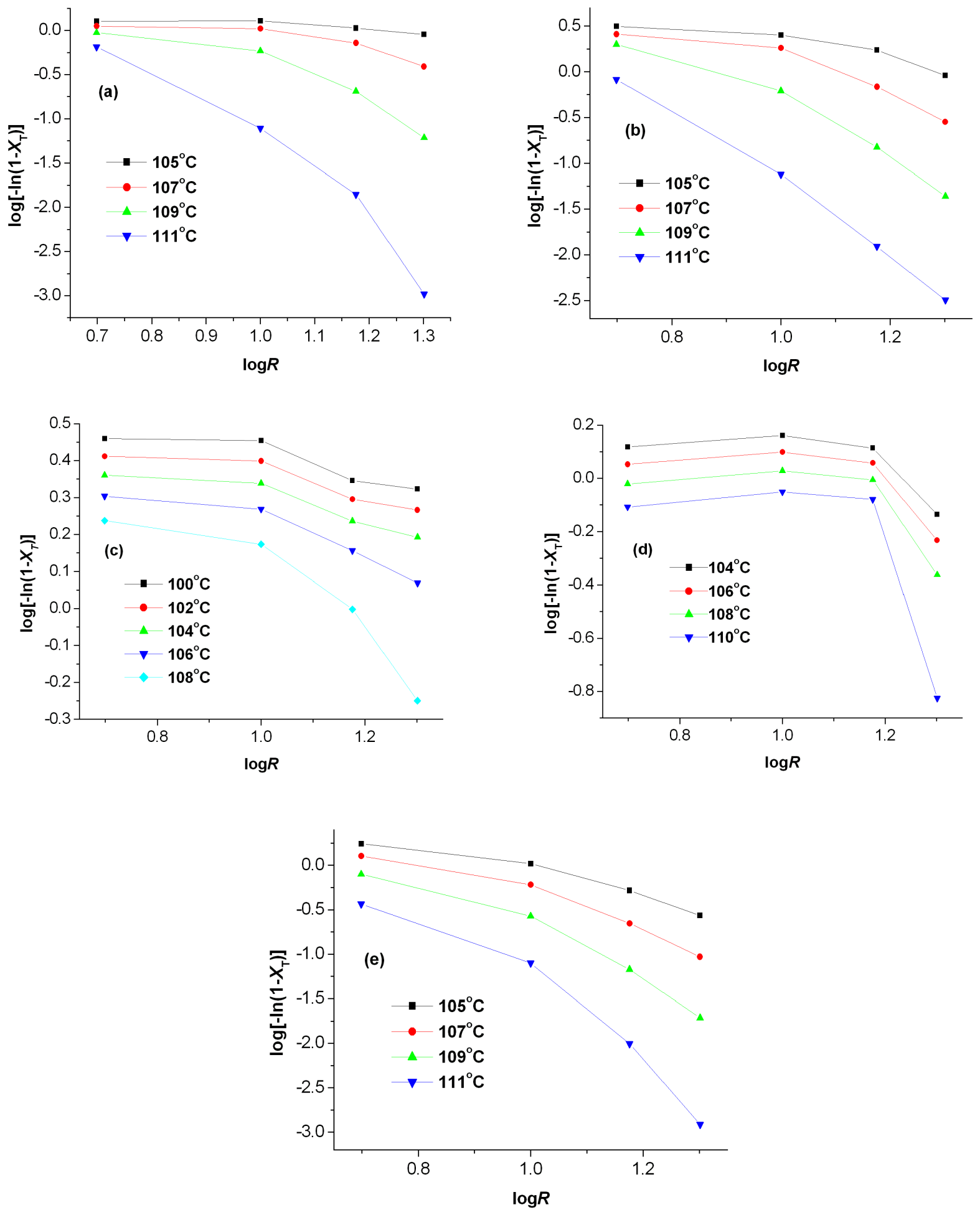

Fig. (2). $\log \left[-\ln \left(1-\mathrm{X}_{T}\right)\right] v s \log R$ plot: (a) PE; (b) PE/MMT1 (MMT = $\left.0.2 \mathrm{wt} \%\right)$; (c) PE/MMT2 (MMT = $\left.1.0 \mathrm{wt} \%\right)$; (d) PE/MMT3 (MMT = $2.4 \mathrm{wt} \%)$; (e) PE/MMT4 (MMT = $4.0 \mathrm{wt} \%)$.

$t=\left(T_{0}-T\right) / R$

Where $T$ is the temperature at time $t, T_{0}$ is the temperature at $t=0$, and $R$ is the cooling rate. Based on this relation, the combination of Avrami equation and Ozawa equation lead to establishment of the following equations $(3,4)[21]$. At given crystallinity $X_{t}$ : $\log \left[-\ln \left(1-X_{t}\right)\right]=\log k+n \log t$

$\log \left[-\ln \left(1-X_{t}\right)\right]=\log K_{(T)}-m \log R$

Where $K_{(T)}$ is the cooling function of nonisothermal crystallization, $m$ is Ozawa index. Combining equations (3) and (4) leads to equation (5):

$\log R=\log F_{(T)}-a \log t$ 

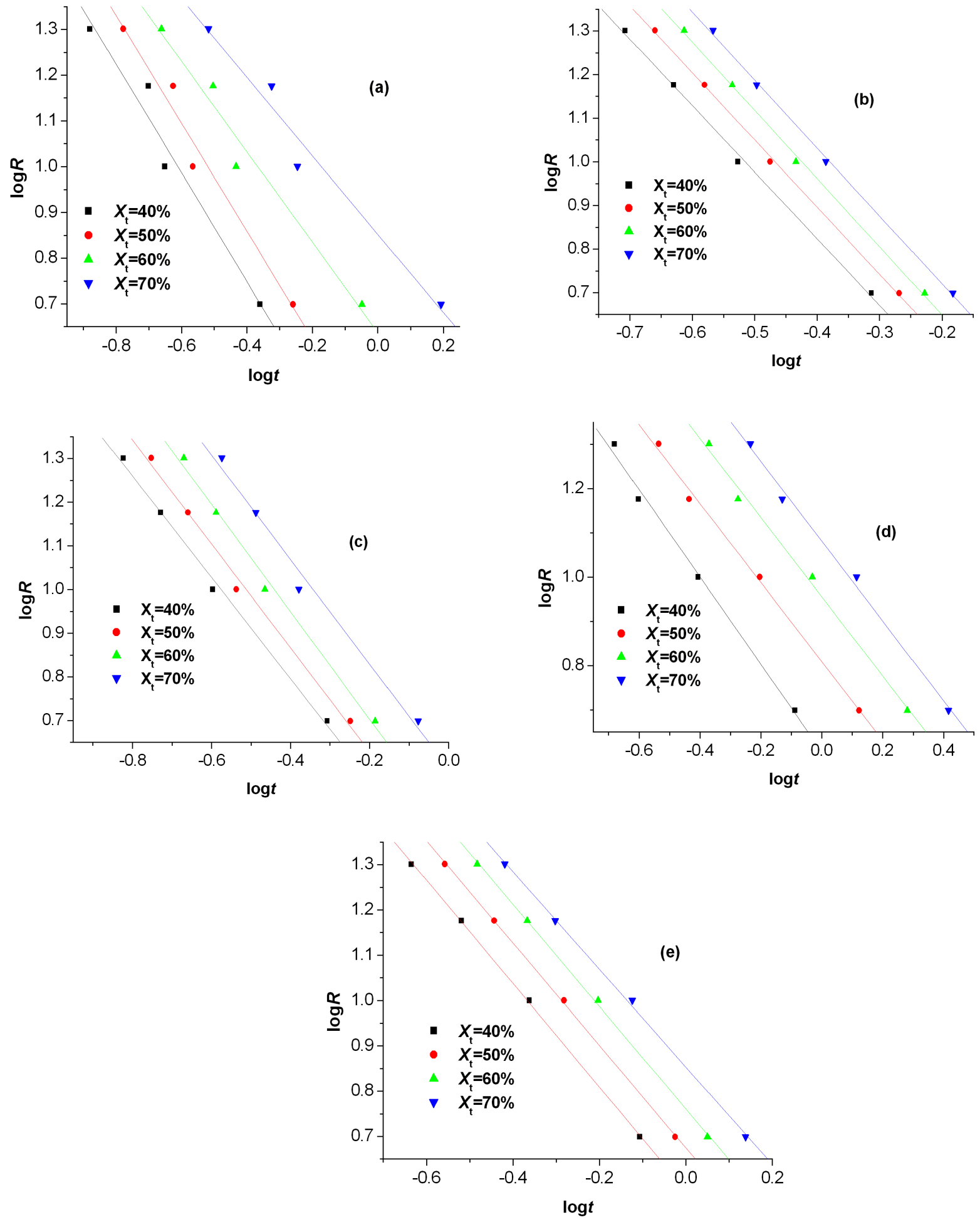

Fig. (3). Curves of $\log R v s \log t$ : (a) PE; (b) PE/MMT1 (MMT = $0.2 \mathrm{wt} \%)$; (c) PE/MMT2 (MMT = $1.0 \mathrm{wt} \%)$; (d) PE/MMT3 (MMT = 2.4 $\mathrm{wt} \%)$; (e) PE/MMT4 (MMT = $4.0 \mathrm{wt} \%)$.

Where $F_{(T)}=\left[K_{(T)} / k\right]^{1 / m}, a=n / \mathrm{m}$. According to this equation, to plot $\log R$ versus $\log t$ at the same crystallinity formed a straight line with $\log F_{(T)}$ the intercept and $-a$ the slope. Herein $F_{(T)}$ represents the required cooling rate to reach certain crystallinity of a given system when the crystallization time is one minute (or one second). So the $F_{(T)}$ is not only well defined in physics, but also applicable in practical use.
Plotting $\log R$ versus $\log t$ gives linear relationship. Both $F_{(T)}$ and $a$ values can be obtained from the intercept and slope of the lines. Fig. (3) depicts such relationship of the PE/MMT nanocomposites with varying MMT contents. Good linearity can be found in these lines and it's easy to ascertain the values of $F_{(T)}$ and $a$. Table 2 lists all the $F_{(T)}$ and 
Table 2. Data of $\boldsymbol{F}_{(T)}$ and $\boldsymbol{a}$ for Different PE/MMT Nanocomposites

\begin{tabular}{|c|c|c|c|}
\hline Sample & $X_{T}(\%)$ & $\boldsymbol{F}_{(T)}\left({ }^{\circ} \mathbf{C}\right)$ & $a$ \\
\hline \multirow[t]{4}{*}{$\mathrm{PE}$} & 40 & 1.88 & 1.19 \\
\hline & 50 & 2.44 & 1.18 \\
\hline & 60 & 4.34 & 0.99 \\
\hline & 70 & 7.12 & 0.86 \\
\hline \multirow[t]{4}{*}{$\mathrm{PE} / \mathrm{MMT} 1(\mathrm{MMT}=0.2 \mathrm{wt} \%)$} & 40 & 1.64 & 1.52 \\
\hline & 50 & 1.91 & 1.54 \\
\hline & 60 & 2.17 & 1.56 \\
\hline & 70 & 2.56 & 1.56 \\
\hline \multirow[t]{4}{*}{ PE/MMT2 $(\mathrm{MMT}=1.0 \mathrm{wt} \%)$} & 40 & 2.15 & 1.16 \\
\hline & 50 & 2.46 & 1.19 \\
\hline & 60 & 2.87 & 1.23 \\
\hline & 70 & 3.89 & 1.20 \\
\hline \multirow[t]{4}{*}{ PE/MMT3 $(\mathrm{MMT}=2.4 \mathrm{wt} \%)$} & 40 & 4.04 & 0.99 \\
\hline & 50 & 6.45 & 0.89 \\
\hline & 60 & 9.03 & 0.89 \\
\hline & 70 & 12.06 & 0.90 \\
\hline \multirow[t]{4}{*}{$\mathrm{PE} / \mathrm{MMT} 4(\mathrm{MMT}=4.0 \mathrm{wt} \%)$} & 40 & 3.81 & 1.14 \\
\hline & 50 & 4.73 & 1.13 \\
\hline & 60 & 5.77 & 1.13 \\
\hline & 70 & 7.14 & 1.08 \\
\hline
\end{tabular}

$a$ values for the investigated samples at varying crystallinities.

For different samples, their values of $a$ is almost the same and the $F_{(T)}$ numbers increased with crystallinities. This indicates that greater cooling rates $\left(F_{(T)}\right)$ are required to realize higher relative crystallinity in the same period, i.e., as for the same material, the higher the cooling rate, the greater the crystallinity odtained for given crystallization time. It's also seen that, to reach the same crystallinity, the $F_{(T)}$ values decreased for all the nanocomposites compared to neat PE. So the introduction of MMT shortened the crystallization time of PE. However, further increase of the MMT loading gave rise to stronger interfacial interaction, thus inhibiting the segment movement or the rate of crystalline growth and increasing the $F_{(T)}$ as a result. Therefore, to arrive at the same relative crystallinity, it's necessary to speed up the cooling rate.

In summary, the combination of Ozawa equation and Avrami equation explains well the nonisothermal crystallization process of PE/MMT nanocomposites. Furthermore, $F_{(T)}$ possesses definite physical significance which is expected to be of practical guidance in fabricating PE wares where certain crystallinities are desired.

\section{CONCLUSIONS}

Ozawa equation alone is difficult to deal with a nonisothermal crystallization process of PE/MMT nanocomposites and the kinetics parameter is also hard to obtain, hence failing to deduce the crystallization mechanism under this circumstance. To consider together the Avrami equation and
Ozawa equation establishes an effective way in studying the nonisothermal crystallization behaviour of the as-synthesized nanocomposites. It's convenient to define the values of $F_{(T)}$ and $a$ that have definite physical significance. The crystallization time shortens upon addition of MMT into PE whereas a further increase of MMT loadings results in improved interface interaction and decreased rates of segment movement and crystalline growth, thus leading to the increase of $F_{(T)}$. As a result, high cooling rates are required to reach the same relative crystallinity.

\section{ACKNOWLEDGEMENT}

We acknowledge the funding from the National Natural Science Foundation of China (NSFC, No. 50103012).

\section{REFERENCES}

[1] Giannelis, E.P. Polymer layered silicate nanocomposites. Adv. Mater., 1996, 8, 29-35.

[2] Wang, Z.; Pinnavaia, T.J. Nanolayer reinforcement of elastomeric polyurethane. Chem. Mater., 1998, 10, 3769-3771.

[3] Kojima, Y.; Usuki, A.; Kawasumi, M.; Okada, A.; Fukushima, Y.; Kurauchi, T.; Kamigaito, O. Mechanical-properties of nylon 6-clay hybrid. J. Mater. Res., 1993, 6, 1185-1189.

[4] Wang, J.; Liu, Z.Y.; Guo, C.Y.; Chen, Y.J.; Wang, D. Preparation of a PE/MT composite by copolymerization of ethylene with in-situ produced ethylene oligomers under a dual functional catalyst system intercalated into MT layer. Macromol. Rapid Commun., 2001, $22,1422-1426$.

[5] Guo, C.Y.; Ma, Z.; Zhang, M.G.; He, A.H.; Ke, Y.C.; Hu, Y.L. Preparation of PE/MMT nanocomposite by monomer intercalation and in situ copolymerization. Chin. Sci. Bull., 2002, 47, 1267-1270.

[6] Qian, J.; Guo, C.Y.; Wang, H.; Hu, Y. Fabrication and characterization of PE/MMT nanocomposites via copolymerization of ethylene and in situ formed $\alpha$-olefins. J. Mater. Sci., 2007, 42, 43504355 . 
[7] Ke, L.; Yang, M.; Zhang, S.; Su, Q. Non-isothermal and isothermal crystallization behavior for nylon66/montmorillonite composites. Acta Polym. Sin., 2002, 472-478.

[8] Liu, L.; Qi, Z.; Zhu, X. Studies on nylon6/clay nanocomposites by melt-Intercalation process. J. Appl. Polym. Sci., 1999, 71, 11131138 .

[9] $\mathrm{Yu}, \mathrm{J} . ; \mathrm{He}, \mathrm{J}$. Crystallization kinetics of maleic anhydride grafted polypropylene ionomers. Polymer, 2000, 41, 891-898.

[10] Seo, Y.; Kim, J.; Kim, Y. Study of the crystallization behaviors of polypropylene and maleic grafted polypropylene. Polymer, 2000, 41, 2639-2646.

[11] Xu, W.B.; Ge, M.L.; He, P.S. Nonisothermal crystallization kinetics of polypropylene/montmoriilonite nanocomposites. J. Polym. Sci. Part B: Polym. Phys., 2002, 40, 408-414.

[12] Fisher, J.C.; Hollomon, J.H.; Turnbull, D. Nucleation. J. Appl. Phys., 1948, 19, 775-784.

[13] Dilorenzo, M.L.; Silvestre, C. Non-isothermal crystallization of polymers. Prog. Polym. Sci., 1999, 24, 917-950.

[14] Grenier, D.R.; Prud'homme, E. Avrami analysis: Three experimental limiting factors. J. Polym. Sci. Part B: Polym. Phys., 1980, 18, 1655-1657.
[15] Xu, W.B.; Ge, M.L.; He, P.S. Nonisothermal crystallization kinetics of polypropylene/montmoriilonite nanocomposites. J. Polym. Sci. Part B: Polym. Phys., 2002, 40, 408-414.

[16] Ma, J.S.; Zhang, S.M.; Qi, Z.N.; Li, G.; Hu, Y.L. Crystallization behaviors of polypropylene/montmorillonite nanocomposites. $J$. Appl. Polym. Sci., 2002, 83, 1978-1985.

[17] Yuan, Q.; Awate, S.; Misra, R.D.K. Nonisothermal crystallization behavior of polypropylene-clay nanocomposites. Eur. Polym. J., 2006, 42, 1994-2003.

[18] Tseng, C.R.; Lee, H.Y.; Chang, F.C. Crystallization kinetics and crystallization behavior of syndiotactic polystyrene/clay nanocomposites. J. Polym. Sci. Part B: Polym. Phys., 2001, 39, 2097-2107.

[19] Gopakumar, T.G.; Lee, J.A.; Kontopoulou, M.; Parent, J.S. Influence of clay exfoliation on the physical properties of montmorillonite/polyethylene composites. Polymer, 2002, 43, 5483-5491.

[20] Ozawa, T. Kinetics of non-isothermal crystallization. Polymer, 1971, 12, 150-158.

[21] Liu, J.P.; Mo, Z.S. Crystallization kinetics of polymers. Polym. Bull., 1991, 26, 199-207.

(C) Shi et al.; Licensee Bentham Open.

This is an open access article licensed under the terms of the Creative Commons Attribution Non-Commercial License (http://creativecommons.org/licenses/by-nc/3.0/) which permits unrestricted, non-commercial use, distribution and reproduction in any medium, provided the work is properly cited. 